\title{
Recalibrating the United Kingdom's local air quality management regime to deliver desired goals
}

\author{
J. W. S. Longhurst, J. Barnes, T. J. Chatterton, E. T. Hayes, \\ J. G. Irwin \& A. O. Olowoporoku \\ Air Quality Management Resource Centre, \\ University of the West of England, UK
}

\begin{abstract}
The UK has operated a sophisticated Local Air Quality Management (LAQM) regime since 1997. This comprises two distinct phases: Review and Assessment and Action Planning. The Review and Assessment is the diagnostic phase and concludes with declaration of an Air Quality Management Area (AQMA) where Air Quality Objectives (AQOs) are exceeded, which then initiates the Air Quality Action Plan intended to provide solutions to the identified problems. More than half of UK local authorities have one or more AQMAs. Air Quality Action Plans are expected to define measures and timescales by which air quality in the AQMA will comply with AQOs. The main source of the air quality exceedence is traffic-related $\mathrm{NO}_{2}$ or $\mathrm{PM}_{10}$. The Review and Assessment phase is effective at diagnosing air quality problems but the Air Quality Action Plan phase cannot yet be judged to be a successful policy intervention. Local authorities have limited powers to initiate direct actions amid concerns about the political impact of measures that will the process affect the car-driving public. In such circumstances local authorities have been unable to get traction on air quality management problems. Central to the LAQM regime is the division of responsibility between central government and local government. Whilst LAQM is a local responsibility, central government's has an overarching role in controlling the regime through framing the process, defining national goals, setting strategic directions, and ensuring appropriate resourcing for national and local actions. Despite this national process guidance and direction local authorities are failing to achieve local air quality improvements at the rate expected when LAQM was introduced.
\end{abstract}


This paper considers the implications of two distinct policy disconnects present in the LAQM process. The first of which is that between the spatial and temporal diagnosis of poor air quality and the solution proffered in the Air Quality Action Plan. Secondly, the disconnection between local actions and the strategic direction and policy intentions offered by central government. A number of changes to the process of LAQM are recommended to reconnect the policy disconnections identified in this paper.

Keywords: Environment Act 1995, air quality management, diagnosis, solutions, United Kingdom.

\section{The need for a new management regime}

The United Kingdom (UK) has a long history of attempts to control air pollution. The control of smoke and $\mathrm{SO}_{2}$ in urban areas, regulation of lead in petrol and continuing downward pressure on industrial air pollution are examples of focused and successful policy interventions in the period 1970-1990. Undoubtedly their success contributed to a view that air pollution was being successfully managed but the scale of the growth in road traffic and consequent emissions, allied with increasing public concern about possible health impacts, challenged the structure and approach of subsequent UK regulatory responses [1].

The existing management framework and available policy tools were found to be inadequate for tackling these continued urban pollution episodes. Different emission sources were controlled by separate government departments and their associated agencies, resulting in a system of control that lacked co-ordination and integration particularly at the local scale. The Government response outlined in the 1990 White Paper on the Environment - This Common Inheritance - was to explore mechanisms for a new approach which would make more effective use of air quality control mechanisms in an integrated and holistic way. The document outlined the scope of actions that can be taken by central and local governments in order to curb the rise of traffic-related air pollution in urban areas [2].

\section{Developing a local air quality management framework}

In the period from 1990 -1995 a new philosophy for air quality management was developed which built upon the existing process by adding an effects-based, risk management approach founded on a suite of Air Quality Objectives (AQOs) based on the recommendations of the Expert Panel on Air Quality Standards [3]. The new framework was introduced in the Environment Act 1995 (Part IV, Air Quality) which set out responsibilities for central and local government. Local management was placed at the heart of the response whilst maintaining, at a national level, a critical role in co-ordination and direction of local actions and the undertaking of such duties most effectively discharged at the level of the nation state. 


\section{Success and failure in LAQM: exploring and defining the policy disconnects}

The primary requirement of the 1995 Environment Act was the preparation of an Air Quality Strategy (AQS) by Government. The AQS was first published in 1997, and reviewed, updated and amended in 2000 and 2007 (with an Addendum in 2003). The AQS considered the historical legacy of air pollution, the contemporary nature of the air pollution challenge, and the adequacy of current controls, measures and priorities. It laid out a new direction for the management of air quality in compliance with the requirements specified in the Environment Act [5]. Together, the Environment Act, 1995 and AQS provide a framework in which national and local actions are required to identify and remediate areas of poor air quality. The Act places a series of duties and responsibilities upon local authorities to review and assess local air quality against specific targets known as AQOs [6]. The original AQS was founded upon the principles of sound science; health effects based regulation, cost-effectiveness, proportionality, sustainability, precautionary approach and subsidiarity which to this day continue to inform its implementation. The AQS therefore sets out a series of AQOs for LAQM covering major pollutants with significant public health risks: lead, CO, 1, 3-butadiene, $\mathrm{SO}_{2}, \mathrm{NO}_{2}$, benzene and $\mathrm{PM}_{10}$. These objectives were introduced as Regulations in 1997, revised in 2000 and amended 2002. A new AQS was published in 2007 [7].

The objectives specified in Regulations represent the Government's judgement of achievable air quality by specified timescales on the evidence of costs and benefits and technical feasibility. The objectives apply in areas where the public may be exposed for the averaging time of the relevant objective such as building facades, public open spaces, pavements and gardens; local authorities undertaking assessments of air quality are under a duty to identify if relevant public exposure exists in any area where exceedence of an air quality objective is identified [8]. Where relevant exposure and exceedence of the objectives exist, local authorities are then required to declare such designated areas as Air Quality Management Areas (AQMAs).

AQMAs are similar in concept to the idea introduced in the Clean Air Act, 1956 of a smokeless zone; although in practice they are more complex entities as they can relate to a wider number of pollutants. Following declaration of an AQMA a local authority is required to develop an Air Quality Action Plan to pursue the achievement of the AQOs detailing both the measures to be taken and the time-scale for their implementation. The Environment Act places a duty on Government to support local authorities through the provision of guidance and other initiatives. This has included the development of high quality national monitoring networks, the creation of $1 \mathrm{~km}$ resolution emissions inventories, the provision of training for local authority personnel, the development of Technical and Policy Guidance documents to assist local authorities in their LAQM duties, and the provision of additional financial assistance to help authorities purchase monitoring equipment and other technical resources. An important support element has been the development of web, telephone and email help desks and 
other support materials to assist, often non-specialist, air quality officers in carrying out their duties [8].

The AQS is dynamic and subject to rolling review to reflect developments in European legislation, technological and scientific advances, improved air pollution modelling techniques and an increasingly better understanding of the socio-economic issues involved in managing air quality and implementing effective Air Quality Action Plans [8]. Similarly, the Air Quality Regulations, which give statutory weight to the air quality objectives, are reviewed periodically to reflect new developments in knowledge and understanding of specific pollutants and their impact on human health.

In parallel with UK developments, the EU has continued its development of strategic air quality management including the Air Quality Framework Directive (96/62/EC) and subsequent daughter directives. As new Daughter Directives emerge these are transposed into UK legislation and, subject to the scale and complexity of the management challenge implied by the Directive they may be incorporated in to the requirements of LAQM. Local authorities have the responsibility to work towards securing the objectives through the process of Review and Assessment and through the development of Air Quality Action Plans [7]. Under the UK Environment Act 1995, local authorities carry out reviews and assessments of air quality to define the contemporary and future state of local air quality in their area. The Review and Assessment is considered by Government to be a continuous cyclical process which may, or may not, lead to the declaration of an AQMA. However with distinct temporal phases of work known as "rounds", during which the Government exercises its power as a Statutory Consultee to appraise the work of local authorities and acts to assure itself that the statutory duties of the local authorities are being undertaken in an appropriate manner.

Local authorities in Great Britain began the process of Review and Assessment in 1998. The first round of the process concluded in 2001 and resulted in some 129 local authorities declaring one or more AQMAs. A second round of Review and Assessment began in 2003, and a third round commenced in 2006. In the interval between each round, local authorities are required to issue an annual Progress Report, the purpose of which is to report new monitoring data, describe any new developments that might affect air quality and to maintain the momentum of air quality management in the local authority.

At the end of second round, some 192 local authorities had declared AQMAs. In the summer of 2008, the third round recorded more than 200 UK local authorities declaring one or more AQMAs. The number of local authorities with AQMAs had grown to 235 at the start of 2010. These AQMAs have principally been declared for $\mathrm{NO}_{2}$, with a significant number of $\mathrm{PM}_{10}$ and a smaller number of $\mathrm{SO}_{2}$ declarations. An AQMA represents the conclusion of a technical assessment of air quality carried out in accordance with central government guidance against the air quality objectives. In declaring an AQMA a local authority will have satisfied itself, relevant stakeholders and Government that a risk of exceeding one or more objectives by the date the objective is to be achieved has been demonstrated in an area in which public exposure for a 
relevant period is or will be present. Details of local authorities with AQMAs may be seen at http://www.airquality.co.uk/laqm/list.php

Following the declaration of an AQMA, a local authority must undertake a Further Assessment of air quality as required by Section 84 of the Environment Act. This assessment is designed to confirm the appropriateness of the original decision, define the boundaries of the declared area and provide information on the emission sources contributing to the exceedence in order to support the preparation of an Air Quality Action Plan as specified by the Environment Act. Although the Act does not specify a timescale for this, the Policy Guidance provided by the Government states that this is expected within 12 to 18 months of the designation of the AQMA [9]. In practice, the development of Air Quality Action Plans has proceeded at a much slower rate than the diagnostic Review and Assessment work. Even where a plan is being implemented there are limited examples of success to report. However of more import is the relative success of the Air Quality Action Plans in managing local air quality. There is little evidence to show that the LAQM regime has led to the reduction of a high concentration of a named pollutant through the actions specified in the Air Quality Action Plan; thereby creating an obvious limitation in the LAQM process in terms of policy disconnect between the diagnosis of the problem and the solutions proffered.

Given the complexity of the contemporary air quality challenge this lack of success might be explainable. The UK has had a LAQM regime in operation since 1997. It has developed a highly sophisticated diagnostic capability but has not been able to replicate such success when proffering solutions to diagnosed problems. Clearly the solution to air quality is not the remediation of a technical problem alone. The challenges to overcome in implementing an Air Quality Action Plan include a complex and shifting mix of contributory features. These include political, economic, public opinion, communication and technical barriers and also issues relating to the organisational capacity and capability of the local authority.

In order to get traction on the failure to deliver effective Air Quality Action Plans the Local Government White Paper, Strong Local Leadership - Quality Public Services, provided English local authorities with AQMAs associated with emissions from transport sources the opportunity to incorporate their Air Quality Action Plans into their Local Transport Plan (LTP) process [10]. The LTP is a separate Government requirement, managed by the Department for Transport, operating to a different reporting timescale to that of LAQM and engaging with transport planning departments which may be in either local or county authorities. The LTP is principally a bidding document for resources from central government to support transport intentions. It sets out plans and policies in relation to a suite of priorities identified by the central government. Thus the LTP appears to offer advantages in respect of calibrating and implementing an air quality improvement plan where transport is the cause of the air quality problem. The lead department for the LTP is generally the transport planning department of a local authority but added complexity arises, in a multi-tier local government arrangement, when the lead is actually in a higher tier of 
government, a county council, other than the district authority with administrative responsibilities for air quality management. Thus the apparent advantage of incorporating the Air Quality Action Plan within the LTP is itself fraught with new and often intractable difficulties. These include the capability of transport professionals to appreciate the complexity and importance of air quality issues relative to all the other "traditional" transport policy concerns such as congestion, accessibility and road safety. These issues might reasonably be assumed to have a more immediate political and economic benefit than air quality considerations and be given a higher priority in the bid and subsequent allocation of expenditure. Evidently, the integration of LAQM and LTP offered the prospect of a more holistic approach to the remediation of poor air quality and the possibility of securing funding under the LTP settlement grant to support the Air Quality Action Plan. Unfortunately and despite these apparent advantages the LTP has been no more successful a policy than the Air Quality Action Plan [11]. The failure of this approach can perhaps best be seen in the decision to remove air quality as a priority for action in the next round of the LTP process.

From inception it was clear that the success of LAQM would require connection between policies, adequate resourcing, clear communication of priorities and a shared ownership of responsibility for achieving outcomes between central and local government [5]. Now, after 13 years of LAQM it is apparent that in substantive areas of policy implementation the extent of policy disconnects between local and central and between solutions and diagnosis is evident and urgently requires corrective action. Firstly, the interconnection between LAQM and other policy packages needs to be made explicit both nationally and locally. Secondly, the communication of the rationale for LAQM and the necessity for action must be framed in acceptable ways for broad public consumption. Thirdly, vested interests must be challenged and finally resourcing of the LAQM regime needs re-examination.

\section{Reconnecting the policies and priorities}

The air quality policy framework in the UK has undergone a radical transformation since 1995. It has exchanged a source-control approach for a complex but integrated, risk management effects-based process of air quality management. The deficiencies in the regime principally relate to the Action Planning process where it can be argued that political and economic risks are more common than in the diagnostic phase of LAQM. The inability of local authorities to implement effective Air Quality Action Plans might be because the plans are poorly constructed and imprecisely calibrated to the problem. This argument may be valid in a few instances but the quality assurance elements of the LAQM regime which requires all plans to be approved by central government or a devolved administration for technical compliance and likely efficacy suggests that this is not a sufficient explanation.

The LAQM process is administrated by Department for Environment, Food and Rural Affairs (Defra) and the Devolved Administrations through local 
authority Environmental Health or other Environmental Service departments. In practice, most of the sources of air pollution are related to the remits of the transport, land-use planning or economic development areas of local government and there is little direct ability for the Review and Assessment process to have a strong effect on these policy areas [9]. In the preparation of Air Quality Action Plans the Environmental Health department will undertake negotiations with transport, land-use planning or economic development areas of local government in order to align, as best as is possible, the air quality resolution within existing policies and processes of governance. Where the local authority has control over the sources of pollution and has been able to establish effective internal and/or external co-ordination and communication systems between different functions, then significant air quality improvements can be seen at the local level even if they do not always succeed in reducing pollution levels to below the objective concentrations.

The current UK approach to the management of air quality, particularly at the local level, is one of a public health orientated environmental management programme, setting out a risk-based framework, leading to targeted, proportionate and cost-effective actions focussed on a single area of the environment. There are clear health-based standards, indicating 'acceptable' and 'unacceptable' levels of air pollution. National policy objectives have been set based on these standards but taking into account technical and economic issues that might affect their attainment. This provides clear target dates for their achievement within a framework allowing assessment of problems at both local and national levels. Therefore, the national policy objectives appears to meet the aims set for it in terms of policy intentions and the clarity of the procedures to diagnose the air quality problem through the Review and Assessment process. However, the situation with Air Quality Action Plans is not as clear. Whilst the procedures are clear, the urgency of the policy intent is not present to the same extent as is seen in the Review and Assessment component of the framework.

The measures within an Air Quality Action Plan are designed to explicitly target the sources contributing to an exceedence of an AQO. In practice this means that traffic sources are the target of the measures and this brings a range of technical, economic and political costs and risks for a local authority. Identifying and managing these risks is now critically important if air quality improvements are to be achieved. Local and central government need to identify new ways of explaining air quality risks and impacts in order to build alliances to deliver improvements. It is probable that the metrics used in explaining air quality are too technical for the majority of the population and it has been suggested that the current information campaigns through which the public and the local government elected members are engaged on the health, economic and social impacts of air pollution are not efficient for real political and social change [12]. Evidence shows that the lack of visible air pollution and its relative intangibility compared to the other shared priorities contributed to the lower importance that was given to air quality within the LTP2 process [11]. If such political tangibility is to be increased, holistic approach to the management of air quality across various policy spheres needs to be taken. 
Since air quality policy is closely linked with a number of other policy areas such as health, transport, land-use planning and climate change, significant steps towards policy integration is needed across central and local government departments. In respect of air quality impacts on health, Defra and Department for Health, and the Devolved Administrations counterparts can work together to develop clearer messages on the impact of air quality, as set out by the Committee on the Medical Effects of Air Pollutants (COMEAP) and other similar bodies. Local authorities can work closely with the Primary Care Trusts during the declaration of an AQMA in order to quantify the health impact of such hotspots and the benefit that may be accrued through their management - in terms of increases in life expectancy, reduction in heart and lung diseases and financial benefits to the National Health Service. On transport, Defra and Department for Transport can work together in aligning the traffic-related AQOs as targets that have to be achieved within the LTP lifecycle. This will ensure that environmental and health impact data are properly used to influence transport planning decision making process at the local level and therefore reduce the institutional complexities due to the separation between the identifying and the correcting party as both are required to meet the same targets and objectives. On climate change, there are opportunities for integrating the two areas of policy due to commonality of sources between $\mathrm{NO}_{2}, \mathrm{PM}_{10}$ and $\mathrm{CO}_{2}$. While shorter journeys (less than 5 miles) have considerably more effect on air quality than on $\mathrm{CO}_{2}$ emissions, the benefits of co-managing both issues together are greater than treating them separately in addition to the media and public attention given to climate change which may help in increasing the political tangibility of air quality management.

\section{Concluding remarks}

In the 13 years of LAQM since the first air quality strategy was published in 1997 there has been a significant enhancement in the ability of decision makers to take account of air quality in routine decision making. The quality of information available to decision makers has improved as the LAQM process has developed appropriate methods for local, repetitive, comprehensive, and quality assured Review and Assessment procedures [13]. These reviews and assessments are able to draw upon high quality emissions and monitoring data via a number of specially commissioned web resources and support structures guiding the LAQM process. Local authorities have begun the difficult transition from simply defining the state of the local atmosphere towards securing Air Quality Action Plan goals [13]. This represents a transition from procedural compliance with the diagnostic process of LAQM towards achievement of improved air quality outcomes. To do this, it will require new means of internal communication and co-operation and external consultation and the ability to confront political and economic vested interest.

Whilst some of the processes and procedures need refinement and enhancement to become effective in providing solutions, the position in terms of diagnosis provides encouragement that the challenge posed by poor air quality 
can be identified and resolved. The flexible, responsive system, which has created a strong flow of information between national and local government, in both directions, is at the heart of the difference between contemporary air quality management and traditional strategies of pollution control. The challenge now is to extend the effective strategies delivering good air quality diagnosis into the Air Quality Action Plan phase so that information about the scale and complexity of local air quality problems is translated into effective delivery strategies for the timely improvement of air quality problems. A critical issue for the further development of air quality management policy and practice will be to ensure appropriate integration with other policies such as transport, health, land-use and climate change. Whether or not political and economic vested interests can be overcome remains to be seen, but if the public health benefits of improved air quality are to be realised then these challenges must be confronted and overcome.

\section{References}

[1] Jewell, T. \& Steele, J. UK regulatory reform and the pursuit of 'sustainable development': the Environment Act 1995. Journal of Environmental Law. 8(2), pp.283-300, 1996

[2] HM Government. This Common Inheritance, CM 1200. Her Majesty's Stationery Office: London, 1990

[3] EPAQS. A Recommendation for a United Kingdom Air Quality Standard for Particles. London: Defra, 1995

[4] HM Government. The Environment (Northern Ireland) Order 2002. London: The Stationary Office, 2002

[5] Longhurst, J.W.S., Lindley, S.J., Watson, A.F.R. \& Conlan, D.E. The introduction of local air quality management in the United Kingdom. A review and theoretical framework. Atmospheric Environment 30, 39753985, 1996

[6] Beattie, C.I., Longhurst, J.W.S. \& Woodfield, N.K. Air quality management: evolution of policy and practice in the UK as exemplified by the experience of English local government. Atmospheric Environment 35, 1479-1490, 2001.

[7] Department for Environment, Food and Rural Affairs Local Air Quality Management Policy Guidance LAQM.PG (09), Defra: London, 2009.

[8] Longhurst, J.W.S., Beattie, C.I., Chatterton, T.J., Hayes, E.T., Leksmono, N.S. \& Woodfield, N.K., Local Air Quality Management as a risk management process: assessing, managing and remediating the risk of exceeding an air quality objective in Great Britain. Environment International 32, 934-947, 2006

[9] Department for Environment, Food and Rural Affairs. The Air Quality Strategy for England, Scotland, Wales and Northern Ireland, Volume 1. Defra: London, 2007 
[10] Department for Transport. Strong local leadership - Quality public services; UK. Local Government and the Regions 2001White Paper Online. http://www.communities.gov.uk/documents/localgovernment/pdf/143810

[11] Olowoporoku, A. O., Hayes, E. T., Leksmono, N. S., Longhurst, J. W. S. \& Parkhurst, G. Managing traffic-related air pollution in English local governments. In: Polis Conference 2009: Unlocking the economic and environmental potential of innovation in urban and regional mobility, Brussels 10-11 December, 2009. Brussels: Polis, 2009

[12] Faulkner, M. \& Russell, P. Review of Local Air Quality Management. A report to Defra and the devolved administrations. Stationery Office: London, 2010 Online: http://www.defra.gov.uk/environment/quality/air/ airquality/local/documents/laqm-report.pdf

[13] Longhurst, J.W.S., Irwin, J.G., Chatterton, T.J., Hayes, E.T., Leksmono, N.S. \& Symons, J.K. The development of effects based air quality management regime. Atmospheric Environment 43 (1) 64-78, 2009. 